\title{
References
}

1. Blavt O.Z. Informatyvni pokaznyky rivnia fizychnoho zdorovia ta fizychnoi pidhotovlenosti studentiv VNZ. Pedahohika, psykholohiia ta medyko-biolohichni problemy fizychnoho vykhovannia i sportu: zb. nauk. prats pid red. Yermakova S.S. 2012; 11: 14-18.

2. Zhamardii V. Kontseptualna model zastosuvannia fitnes-tekhnolohii na zaniattiakh iz fizychnoho vykhovannia studentiv. Vyshchyi derzhavnyi navchalnyi zaklad Ukrainy. "Ukrainska medychna stomatolohichna akademiia", Pedahohichni nauky: teoriia, istoriia, innovatsiini tekhnolohii. 2018. № 3. S. 77-88.

3. Kashuba V, Futornыi S, Khabynets T, Lopatskyi S. K voprosu povыshenyia эffektyvnosty fyzycheskoho vospytanyia zanymaiushchykhsia fyzycheskymy uprazhnenyiamy s yspolzovanyem tekhnolohycheskykh ynnovatsyi. Molodizhnyi naukovyi visnyk Skhidnoievropeiskoho natsionalnoho universytetu im. Lesi Ukrainky. 2017; 27: 46-52.

4. Kashuba V, Andrieieva O, Goncharova N, Kyrychenko V, Karr I, Lopatskyi S, Kolos M. Physical activity for prevention and correction of postural abnormalities in young women. Journal of Physical Education and Sport. University of Pitesti, Romania. 2019; 19 (2): 500-6.

5. Maksymova K.V, Mulyk K.V. Aktualni pytannia zberezhennia ta zmitsnennia zdorovia studentok 17-21 rokiv vyshchykh navchalnykh zakladiv za rakhunok fizkulturno-ozdorovchykh fitnes-zaniat. Visnyk Kamianets-Podilskoho natsionalnoho universytetu imeni Ivana Ohiienka. Fizychne vykhovannia, sport i zdorovia liudyny. 2017; 10: 301-11.

Цитування на цю статтю:

Хлопецький ВМ., Курилюк СІ. Вплив технології корекції негативних психічних станів студентів засобами оздоровчого фітнесу на їх фізичний стан. Вісник Прикарпатського університету. Серія: Фізична культура. 2019 Листоп 28; 34: 145-153

\begin{tabular}{|c|c|}
\hline Відомості про автора: & Information about the author: \\
\hline $\begin{array}{l}\text { Хлопецький Василь Михайлович }- \text { аспірант } \\
\text { кафедри теорії та методики фізичної культури і } \\
\text { спорту, ДВНЗ "Прикарпатський національний } \\
\text { університет імені Василя Стефаника" (Івано- } \\
\text { Франківськ, Україна) }\end{array}$ & $\begin{array}{l}\text { Khlopetskyi Vasyl Mykhailovych - post-graduate } \\
\text { student of the Department of Theory and Methods of } \\
\text { Physical Culture and Sports, Vasyl Stefanyk } \\
\text { Precarpathian National University (Ivano-Frankivsk, } \\
\text { Ukraine) }\end{array}$ \\
\hline \multicolumn{2}{|l|}{$\begin{array}{l}\text { e-mail upa231@ukr.net } \\
\text { https://orcid.org/0000-0002-9600-6866 }\end{array}$} \\
\hline $\begin{array}{l}\text { Курилюк Серсій Іванович-аспірант кафедри теорії } \\
\text { та методики фізичної культури і спорту, ДВНЗ } \\
\text { "Прикарпатський національний університет імені } \\
\text { Василя Стефаника" (Івано-Франківськ, Україна). }\end{array}$ & $\begin{array}{l}\text { Kuryliuk Serhii Ivanovych - Candidate of Psy- } \\
\text { chological Sciences (Ph.D.), Associate Professor of } \\
\text { the Department of Theory and Methods of Physical } \\
\text { Culture and Sports, Vasyl Stefanyk Precarpathian } \\
\text { National University (Ivano-Frankivsk, Ukraine) }\end{array}$ \\
\hline
\end{tabular}

УДК 615.825: 616.711-001

Михайло Дмитрук, Віра Рокошевська

doi: 10.15330/fcult.34.153-160

\section{ДІАГНОСТИКА ТА ВИЗНАЧЕННЯ ОСНОВНИХ РУХОВИХ ПОРУШЕНЬ ПАТЕРНУ ХОДЬБИ У ОСІБ ПІСЛЯ ПЕРЕНЕСЕНОГО МОЗКОВОГО ІНСУЛЬТУ}

Мета. Встановити основні порушення ходьби у осіб після перенесеного мозкового інсульту. Методи. Визначали та аналізували відхилення патерну ходьби иляхом обстеження 60 осіб після перенесеного мозкового інсульту. Обстеження кінематики ходьби було виконано за допомогою методу Ranco Observershional Gait Anylazis. Результати. Встановлено основні причини порушень патерну ходьби у трьох ключових моментах, ще включать в себе вісім фаз ходьби. Найчастіші порушення патерну ходьби, які виникають у осіб після перенесеного мозкового інсульту є наступними: інверсія стопи присутня в 93,3\% паџієнтів основної групи та в 90\% групи порівняння; у 96,6\% основної та у 
93,3\% порівняльної груп зустрічалося надмірне плантарне згинання стопи; надмірне розгинання колінного суглобу виявлено у 86,6\% основної та у 83,3\% порівняльної груп; приведення стегна під час ходьби спостерігалося у 66,6\% пацієнтів основної та у 70\% порівняльної груп, а обмежене згинання 6 кульшовому суглобі зустрічалося у 53,3\% та 60\% пацієнтів основної та порівняльної груп; в 63,3\% основної та в 56,6\% порівняльної груп виявлено іпсилатеральне опадання тазу, а контрлатеральний нахил тулоба вбік спостерігався у 50\% основної та в 46,6\% порівняльної груп.

Висновок. Обстеження патерну ходьби та вміння правильно його ідентифікувати є одним 3 ключових моментів формування об'єктивно правильного реабілітаційного втручання.

Ключові слова: інсульт, патерн ходьби.

Aim. Establish major walking disorders in individuals after a stroke. Methods. The deviation of the gait pattern was determined and analyzed by examining 60 individuals after a stroke. Walking kinematics were examined using the Ranco Observershional Gait Anylazis method. Results. The main causes of gait disturbances have been identified in three key moments, which will include eight walking phases. The most frequent gait disturbances that occur in individuals after a stroke are the following: foot inversion is present in $93.3 \%$ of the patients in the main group and in $90 \%$ of the comparison group; in $96.6 \%$ of the main and $93.3 \%$ of the comparative groups there was excessive plantar flexion of the foot; excessive knee extension revealed in $86.6 \%$ of the main and $83.3 \%$ of the comparative groups; femoral alignment during walking was observed in $66.6 \%$ of patients in the main and $70 \%$ of the comparison groups, and limited flexion in the hip joint was observed in $53.3 \%$ and $60 \%$ of patients in the main and comparative groups; In $63.3 \%$ of the main and $56.6 \%$ of the comparative groups ipsilateral pelvic tingling was found, and the contralateral tilting of the trunk was observed in $50 \%$ of the main and $46.6 \%$ of the comparative groups.

Conclusion. Examining the walking pattern and being able to correctly identify it is one of the key points in forming an objectively correct rehabilitation intervention.

Keywords: stroke, walking pattern.

Постановка проблеми й аналіз результатів останніх досліджень. Внаслідок високого темпу життя, щоденних стресів і малорухливого способу життя в Україні з кожним роком молодіють цереброваскулярні захворювання. Згідно офіційних даних MO3 України, станом на 2015 рік в Україні було зареєстровано 2551654 хворих 3 різними формами цереброваскулярної патології.

Відомо, що інсульт проявляється не тільки когнітивними порушення, а й руховими розладами. Останні в свою чергу викликають паралічі, парези кінцівок, або їх частини, м'язів мімічної мускулатури та язика $[5,6,7,11]$. Будь-які рухові порушення дають поштовх до зміни патерну ходьби. Саме тому актуальними і необхідними $є$ використання ефективних клінічних інструментів діагностики функції ходьби та правильна ідентифікація рухових порушень патерну $[1,2,3,4]$.

Дослідження виконується згідно зі зведеним планом науково-дослідної роботи на 2016-2020 р. у рамках теми 4.2 "Теоретико-методичні основи фізичної реабілітації неповносправних з порушенням діяльності опорно-рухового апарату та дихальної систем”.

Мета дослідження - встановлення основних порушень ходьби у осіб після перенесеного мозкового інсульту.

Методи дослідження. Визначали та аналізували відхилення патерну ходьби шляхом обстеження 60 осіб після перенесеного мозкового інсульту. Обстеження кінематики ходьби було виконано за допомогою методу Ranco Observershional Gait Anylazis [16].

Шляхом спостереження здійснювали ідентифікацію основних відхилень ходи пацієнта і пряме втручання стосовно тих розладів, які найбільше порушують ходьбу. Дане відхилення порівнювали з нормальними характеристиками ходи та їхньою функцією (табл. 1). Спостережній аналіз проводили безпосередньо під час ходи пацієнта босоніж з оголеними ногами вище колінних суглобів або на відео, яке зафіксовано в процесі ходьби під відповідними ракурсами та у правильних площинах: у фронтальній (спереду та ззаду), а також у сагітальній площинах (кінцівка, яка тестується ближче до камери) і звертали увагу на рухи тазу та тулуба. 
Rancho observational gait analysis

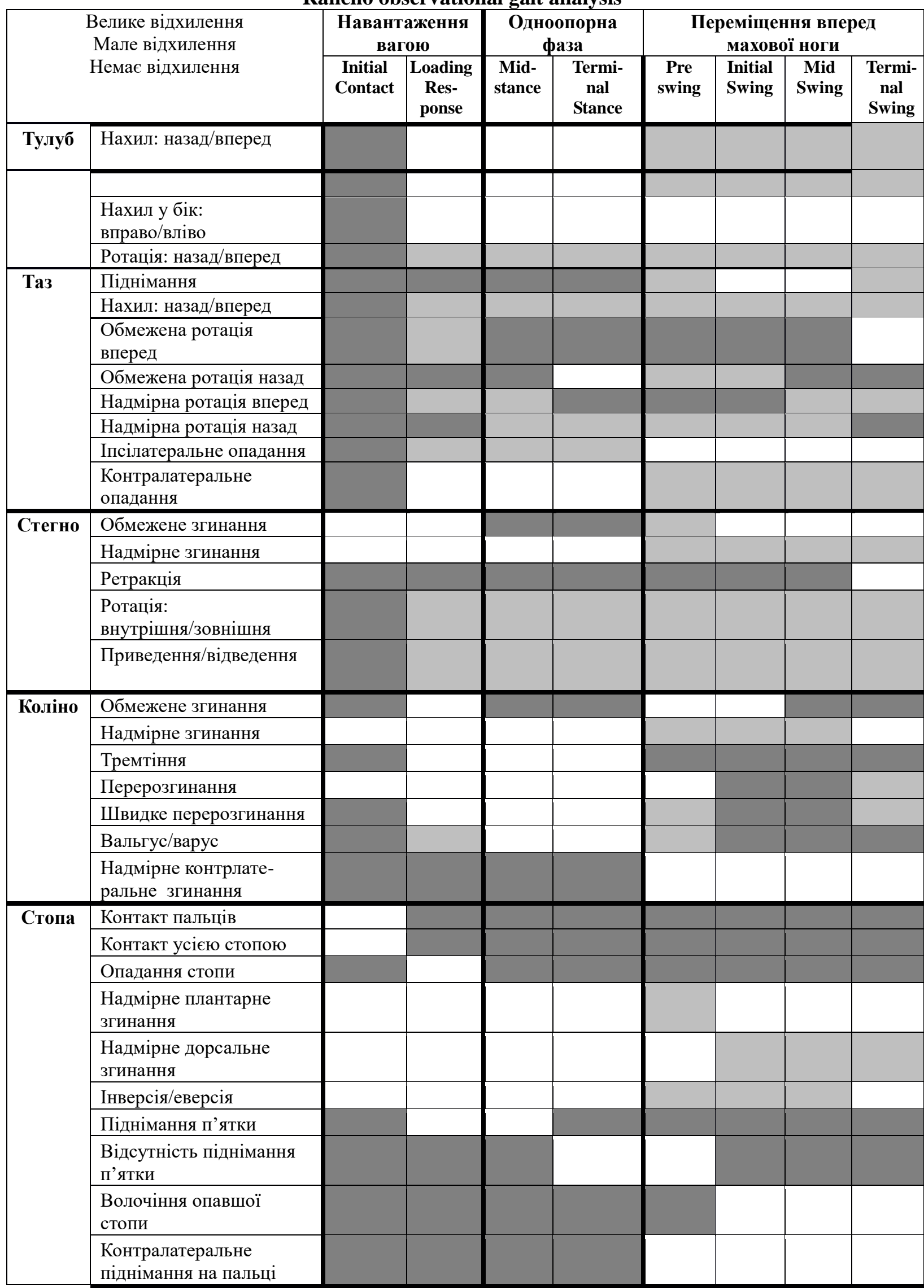




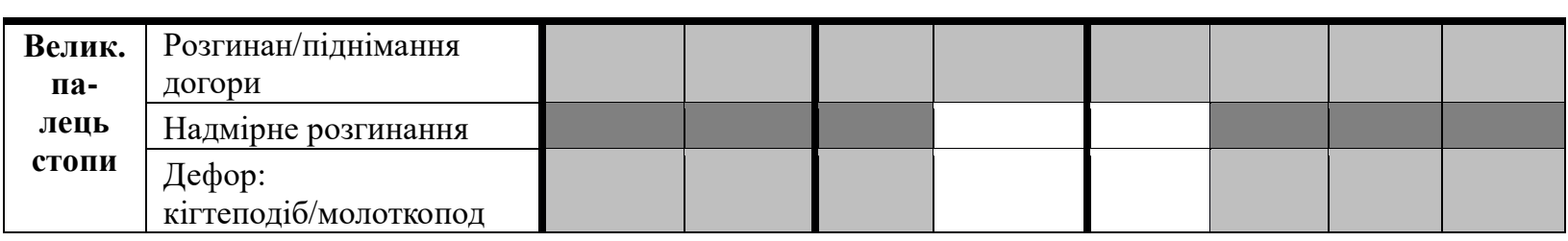

У ході дослідження було проведено первинне обстеження патерну ходьби у двох групах (контрольна та порівняльна) по 30 осіб в кожній (табл. 2).

Таблиия 2

Рухові розлади патерну ходьби, \%

\begin{tabular}{|c|c|c|}
\hline Відхилення (стопа) & Основна група (ОГ) & Група порівняння (ГП) \\
\hline Волочіння опавшої стопи & 33,33 & 36,67 \\
\hline Піднімання п'ятки & 0,00 & 0,00 \\
\hline Інверсія/Еверсія стопи & 93,33 & 90,00 \\
\hline $\begin{array}{c}\text { Надмірне дорсальне } \\
\text { згинання } \\
\end{array}$ & 0,00 & 0,00 \\
\hline $\begin{array}{c}\text { Надмірне плантарне } \\
\text { згинання }\end{array}$ & 96,67 & 93,33 \\
\hline Контакт усією стопою & 16,67 & 13,33 \\
\hline Контакт пальців & 3,33 & 3,33 \\
\hline Волочіння опавшої стопи & 13,33 & 10,00 \\
\hline Відхилення (коліно) & Основна група (ОГ) & Група порівняння (ГП) \\
\hline $\begin{array}{l}\text { Надмірне контрла- } \\
\text { теральне згинання }\end{array}$ & 16,67 & 13,33 \\
\hline Вальгус/Варус & 3,33 & 3,33 \\
\hline Швидке перерозгинання & 13,33 & 10,00 \\
\hline Перерозгинання & 86,67 & 83,33 \\
\hline Тремор & 6,67 & 10,00 \\
\hline Надмірне згинання & 3,33 & 0,00 \\
\hline Обмежене згинання & 6,67 & 13,33 \\
\hline Відхилення (стегно) & Основна група (ОГ) & Група порівняння (ГП) \\
\hline Приведення/Відведення & 66,67 & 70,00 \\
\hline $\begin{array}{c}\text { Ротація } \\
\text { зовнішня/внутрішня }\end{array}$ & 30,00 & 26,67 \\
\hline Ретракція & 13,33 & 10,00 \\
\hline Надмірне згинання & 10,00 & 16,67 \\
\hline Обмежене згинання & 53,33 & 60,00 \\
\hline Відхилення (Таз) & Основна група (ОГ) & Група порівняння (ГП) \\
\hline $\begin{array}{c}\text { Контрлатеральне } \\
\text { опадання }\end{array}$ & 6,67 & 10,00 \\
\hline Іпсилатеральне опадання & 63,33 & 56,67 \\
\hline Надмірна ротація назад & 0,00 & 0,00 \\
\hline
\end{tabular}




\begin{tabular}{|c|c|c|}
\hline Надмірна ротація вперед & 3,33 & 3,33 \\
\hline Обмежена ротація назад & 0,00 & 0,00 \\
\hline Обмежена ротація вперед & 0,00 & 0,00 \\
\hline Нахил: назад/вперед & 6,67 & 3,33 \\
\hline Нахил вправо/вліво & 50,00 & 46,67 \\
\hline
\end{tabular}

3 табл. 2 видно, що найчастіші порушення патерну ходьби, які виникають у осіб після перенесеного мозкового інсульту є наступними: інверсія стопи присутня в 93,3\% пацієнтів основної групи та в 90\% групи порівняння; у 96,6\% основної та у 93,3\% порівняльної груп зустрічалося надмірне плантарне згинання стопи; надмірне розгинання колінного суглобу виявлено у 86,6\% основної та у 83,3\% порівняльної груп; приведення стегна під час ходьби спостерігалося у 66,6\% пацієнтів основної та у 70\% порівняльної груп, а обмежене згинання в кульшовому суглобі зустрічалося у 53,3\% та $60 \%$ пацієнтів основної та порівняльної груп; в 63,3\% основної та в 56,6\% порівняльної груп виявлено іпсилатеральне опадання тазу, а контрлатеральний нахил тулоба вбік спостерігався у 50\% основної та в 46,6\% порівняльної груп.

Наведені вище рухові розлади найбільш спотворюють та порушують патерн на наступних фазах ходьби: плантарне згинання стопи, інверсія стопи фаза - Pre-swing; надмірне розгинання колінного суглобу виникало на фазі Mid stance; приведення стегна у фазах - Inicial contact, Loading response, Terminal swing; а іпсилатеральне опадання тазу у фазах - Inicial swing, Mid stance; нахили тулоба вправо-вліво у фазі - Inicial swing.

У ході дослідження ми посилалися на дані Медичного центру Ранчо Лос Амігос, що займається діагностикою патерну ходьби. Вчені лабораторії виділяють 8 фаз ходьби: початковий контакт; етап завантаження стопи; середина опорної фази; завершальний етап опорної фази; підготовчий етап махової фази; початковий етап махової фази; середній етап махової фази; завершальний етап махової фази. Ранчо Лос Амігос та доктор Жаклін Перрі [15], розробили концепції критичних моментів патологічної ходьби у восьми іiі фазах. Критичним моментом автори вважають спільний рух або певне положення, що вносить значне порушення при здійсненні ходьби в одній з восьми фаз $[2,15,16,19]$.

Таким чином, фізіологічна ходьба містить 3 ключові моменти, які включать в себе вісім фаз.

Навантаження вагою, одноопорна фаза та переміщення вперед махової ноги $\epsilon$ основними ключовими моментами ходьби. Ключовий момент навантаження вагою включає в себе дві фази ходьби: початковий контакт та завантаження стопи. У даних фазах ходьби виникають наступні порушення: контакт передньою частиною та всією підошвою стопи, тремтіння та перерозгинання гомілки в колінному суглобі.

Контакт передньою частиною стопи обумовлений надмірним плантарним згинанням (96,6\% - ОГ, 93,3\% - ГП), обмеженим згинанням в кульшовому та колінному суглобі підчас фази завантаження стопи. Виникає дане порушення за відсутності руху гомілки до переду.

Контакт передньою та всією підошвою стопи виникає за рахунок контрактури гомілково ступневого суглоба, спастики чи гіпертонусу плантарних м'язів згиначів, слабкості дорсальних згиначів та чотириголового м'язу стегна, пропріорецептивних розладів та болю в стопі.

Тремтіння в коліні (зустрічалося в 6,6\% - ОГ та в 10,0\% - ГП) виникає за невідповідності згинання та розгинання у колінному суглобі під час однієї з фаз ходьби. Результатом тремору є втрата стабільності та швидке перерозгинання коліна. Перероз- 
гинання в коліні $(86,6 \%$ - ОГ та у $83,3 \%$ - ГП) в основному починається підчас завантаження стопи.

До основних причин тремору та перерозгинання коліна належать порушення моторного контролю, слабкості та спастичності чотириголового м'язу стега, спастичності плантарних м'язів згиначів стопи.

Одноопорна фаза включає в себе середину опорної фази та завершальний етап опорної фази. До основних порушень під час одноопорної фази ходьби належить: надмірне плантарне та дорсальне згинання стопи, стегна та колінного суглобу, контрлатеральне опадання тазу, нахил тулуба вперед та вбік $[13,14,16,17]$.

За умови повного контакту стопи 3 опорою виявлені наступні розлади ходьби: надмірне дорсальне згинання стопи, в кульшовому та колінному суглобах. Ці зміни викликають м'язову активність чотириголового м'язу, який в середині опорної фази немає активності.

До основних причин надмірного дорсального згинання та надмірного згинання в кульшовому i колінному суглобах належать слабкість плантарних м'язів-згиначів, контрактура колінного та кульшового суглобів, спастичність м'язів-згиначів коліна. Надмірне плантарне згинання може супроводжуватися швидким перерозгинанням та перешкоджатиме руху тіла вперед. Воно зумовлене контрактурою гомілково ступневого суглобу, спастичністю плантарних м'язів-згиначів, розладами пропріорецептивної чутливості та слабкості чотириголового м'язу стегна. Якщо надмірне плантарне згинання виникає в фазі опори, коли п'ята $є$ піднята над поверхнею землі, воно спричине конрактуре гомілково ступневого та колінного суглобів, спастичність плантарних м'язів згиначів стопи, гомілки та різниці довжини фаз різних ніг $[2,15,16,18]$.

Контрлатеральне опадання тазу встановлено у 6,6\% ОГ та в 10\% ГП. Дане порушення виникає у фазі опори за рахунок слабкості м'язів, які забезпечують відведення стегна. Нестабільність в тазовому поясі збільшує енергетичні витрати пацієнта та може бути однією з причин бокового нахилу тулуба. Цей компенсаторний рух може вказувати також і на інші проблеми. Він залежить від фази ходьби у якій виникає та сторони на якій відбувається. Атипові, тривалі рухи в тулубі призводять до болю в попереку. При цьому виникає боковий нахил тулуба за рахунок іпсилатерального болю в кульшовому суглобі, компенсаторного руху для допомоги контрлатеральній кінцівці в маховій фазі та слабкості відвідніх м'язів стегна.

Нахил тулуба до переду $(6,6 \%$ - ОГ та $3,3 \%$ - ГП) часто супроводжується у всіх фазах ходьби. Цей розлад ініціює порушення координації пацієта та збільшує енергетичні затрати і виникає за рахунок слабкості м'язів розгиначів стегна, контрактури в кульшовому суглобі, розлади пропріорецепції.

Переміщення вперед махової ноги є останнім ключовим моментом ходьби та включає в себе наступні фази: підготовчий та початковий, середній та завершальний етапи махової фази. Обмежене згинання коліна $(6,6 \%$ - ОГ, $13,3 \%$ - ГП) у підготовчій фазі махової ноги викликано спастичністю чотириголового м'язу стегна, порушенням селективного контролю, слабкістю плантарних згиначів та болю в гомілково ступневому суглобі. Дане відхилення викликане зазвичай за відсутності достатнього плантарного згинання та передує надмірному дорсальному згинанню на завершальному етапі опорної фази.

Обмежене згинання коліна на початковому етапі махової фази, зазвичай починається у підготовчій фазі та є першочерговим механізмом забезпечення кліренсу стопи, тим не менше необхідно диференціювати причини надмірного плантарного згинання, оскільки воно також може бути викликане розладами функцій стопи. До найбільш імовірних причин обмеженого згинання коліна відносять всі причини, що виникають на 
підготовчому етапі махової фази, а саме, слабкість м'язів стабілізаторів кульшового та колінного суглобів й спастичність м'язів розгиначів стегна.

Недостатнє розгинання $(3,3 \%$ - ОГ та $0,0 \%$ - ГП) в колінному суглобі на завершальному етапі махової фази $є$ основним розладом, що здійснює вплив на довжину кроку. Під час діагностики ходьби важливим $\epsilon$ виявлення основних причин даного порушення до яких входить: слабкість чотириголового м'язу стегна, розгинальна контрактура колінного суглобу, порушення моторного контролю, компенсаторні механізми. Вкрай рідко недостатнє розгинання в колінному суглобі викликане надмірною ротацією тазу у горизонтальній площині. Це викликано деформацією кісток тазу і терапія таких процесів потребує оперативного втручання $[1,2,13,14,15,16]$.

На другому етапі дослідження обстежено кінематичні параметри ходьби 60-ти осіб після перенесеного мозкового інсульту. Встановлено, що до найчастіших порушень ходьби належать: надмірне плантарне згинання $(96,6 \%-$ ОГ, $93,3 \%-\Gamma П)$ та інверсія стопи $(93,3 \%$ ОГ та в 90\% - ГП), перерозгинання колінного суглобу $(86,6 \%$ - ОГ та у $83,3 \%$ - ГП), приведення стегна $(66,6 \%$ - ОГ пацієнтів та у $70 \%$ - ГП), обмежене згинання коліна $(6,6 \%$ - ОГ, $13,3 \%$ - ГП), іпсилатеральне опадання тазу $(6,6 \%-$ ОГ та в $10 \%$ - ГП) та контрлатеральний нахил тулоба (50\% - ОГ та в 46,6\% - ГП). Піднімання п'яти та надмірного дорсального згинання стопи, ротації тулоба назад та вперед в ході дослідження не виявлено. Встановлено основні причини порушень патерну у трьох ключових моментах у осіб після перенесеного мозкового інсульту.

\section{Висновок.}

Обстеження патерну ходьби та вміння правильно визначити порушення патерну ходьби є одним 3 ключових моментів формування об'єктивно правильного реабілітаційного втручання. Отже, правильне обстеження патерну, знання та розуміння причин можливих порушень дозволить в подальшому сформувати ефективний алгоритм реабілітаційного втручання спрямованого на відновлення чи компенсацію ходьби у осіб після перенесеного мозкового інсульту.

1. Берштейн НА. Физиология движений и активность. М.: Медицина, 1990. 494 с.

2. Виленский БС, Яхно НН. Ишемический инсульт. СПб.: Фолиант, 2007. 288 с.

3. Витензон А. С. Закономерности нормальной и патологической ходьбы человека. М.: ЦНИИПП, 1998. $271 \mathrm{c}$.

4. Діагностика, комплексне лікування, реабілітація, профілактика і організаційні заходи 3 питань церебрального інсульту: навч.-метод. посібник для слухачів системи до/та післядипл. підгот., лікарів всіх спец. / І. Зозуля та ін. К., 2005. 72 с.

5. Епифанов ВА. Восстановительная медицина. М.: ГЭОТАР - Медиа, 2007. 592 с.

6. Завалишин ИА, Бархатова ВП. Спастичность // Журн. Невропат. и психиатр. 1986. № 4. С. $532-536$.

7. Зінченко ОМ, Міщенко ТС. Стан неврологічної служби в Україні в 2015 році. Харків; 2016. 23 с

8. Иващенко ЕН. Социально-гигиенические аспекты инвалидности вследствие травм различных локализаций и потребность инвалидов в медико-социальной помощи: автореф. дис. ... канд. мед. наук. М., 1994. 33 с.

9. Кадыков АС. Восстановление нарушенных функций и социальная реадаптация больных, перенесших инсульт (основные факторы реабилитации): автореф. дис. ... д-ра мед. наук (в форме начного доклада). М., 1991.

10. Мухін ВМ. Фізична реабілітація. К.: Олімпійська література, 2005.

11. Wolfe C. D. A. The impact of stroke // Brit. Med Bull. 2000. Vol. 56, № 2. P. 275-286.

12. Shultz SJ et al. Examination of musculoskeletal injuries. 2nd ed, North Carolina: Human Kinetics, 2005. P. 55-60.

13. Loudon J, et al. The clinical orthopedic assessment guide. 2nd ed. Kansas: Human Kinetics, 2008. P. 395408.

14. Demos, Gait analysis, (http: //www.ncbi.nlm.nih.gov/books/NBK27235/ (https: //www.ncbi.nlm. nih.gov /books/NBK27235/)), 2004.

15. Perry J, Giovan P. Harris Lj. et al. The determinants of muscle action in the hemiparetic lower extremity. Clin Orthop 131: 71-89. 1978. 
16. Rancho Los Amigos National Rehabilitation Center, - LAREI, 2001.

17. Hacke W. Neurology / Hacke W., Brott T.,Caplan L.R. et al. 1999. Vol. 53. P. 3-14.

18. Malanga $G$ and Delisa J.A. Section One: Clinical Observation. Office of rehabilitation Research and Development No Date. http://www.rehab.research.va.gov/mono/gait/malanga.pdf.

19. Standford School of medicine \#2 Gait Abnormalities http://stanfordmedicine25.stanford. edu/ the25/gait.html (http://stanfordmedicine25.stanford.edu/the25/gait.html) (Accessed 5 February 2012.

\section{References}

1. Ivashchenko EN. Socio-hygienic aspects of disability due to traumas of different localizations and the need of persons with disabilities in medical and social care: Author's abstract. diss. ... Cand. honey. Sciences - M., 1994. $33 \mathrm{~s}$

2. Kadykov AS Restoration of impaired functions and social readaptation of stroke patients (the main factors of rehabilitation): Author's abstract of the dissertation on competition of a scientific degree of the doctor of medical sciences (in the form of a night report). M., 1991.

3. Mukhin VM Physical rehabilitation. K.: Olympic Literature, 2005.

4. Shultz SJ et al. Examination of musculoskeletal injuries. 2nd ed, North Carolina: Human Kinetics, 2005. P. 55-60.

5. Epifanov VA. Restorative medicine. M.: GEOTAR - Media, 2007. $592 \mathrm{s.}$

6. Zavalishin IA, Barkhatova VP. Spasticity // Journal. Neuropath. and a psychiatrist. 1986. № 4. P. $532-536$.

7. Zinchenko OM, Mishchenko TC. Neurological Service in Ukraine in 2015. Kharkiv, 2016. 23 p.

8. Wolfe C. D. A. The impact of stroke // Brit. Med Bull. 2000. Vol. 56 No. 2. P. 275-286.

9. Bershtein NA. Physiology of Movements and Activity / NA Bershtein, Moscow: Medicine, 1990. 494 p.

10. Vilensky BS, Yahno NN. Ischemic stroke. St. Petersburg: Tome, 2007. 288 p.

11. Wittenson AS. Patterns of normal and pathological walking of a person. M.: CNIIPP, 1998. 271 p.

12. Diagnosis, comprehensive treatment, rehabilitation, prevention and organizational measures for cerebral stroke: Educ.-method. System Guide for pre- and post-graduate students. prep., doctors of all specialties / Zozulya I. and others. K., 2005. 72 p.

13. Rancho Los Amigos National Rehabilitation Center, - LAREI, 2001.

14. Perry J Giovan P. Harris Lj. et al. The determinants of muscle action in the hemiparetic lower extremity. Clin Orthop 131:71 - 89. 1978.

15. Standford School of medicine \#2 Gait Abnormalities http://stanfordmedicine25.stanford.edu/the25/gait.html

16. Loudon J, et al. The clinical orthopedic assessment guide. 2nd ed. Kansas: Human Kinetics, 2008. P. 395-408.

17. Demos, Gait analysis, (http: //www.ncbi.nlm.nih.gov/books/NBK27235/ (https: //www.ncbi.nlm. nih.gov /books/NBK27235/)), 2004.

18. Hacke W., Brott T.,Caplan L.R. et al. Neurology. 1999. Vol. 53. P. 3-14.

19. Bershtein NA Physiology of Movements and Activity. M.: Medicine, 1990. 494 p.

\section{Цитування на цю статтю:}

Дмитрук МБ, Рокошевська ВВ. Діагностика та визначення основних рухових порушень патерну ходьби у осіб після перенесеного мозкового інсульту. Вісник Прикарпатського університету. Серія: Фізична культура. 2019 Листоп 27; 34: 153-160

\begin{tabular}{|c|c|}
\hline Відомості про автора: & Information about the author: \\
\hline $\begin{array}{l}\text { Дмитрук Михайло Богданович - аспірант, Львів- } \\
\text { ський державний університет фізичної культури } \\
\text { імені Івана Боберського (Львів, Україна) }\end{array}$ & $\begin{array}{l}\text { Dmytruk Mykhailo Bohdanovych - post-graduate } \\
\text { student, Lviv State University of Physical Culture } \\
\text { (Lviv, Ukraina) }\end{array}$ \\
\hline \multicolumn{2}{|l|}{$\begin{array}{l}\text { e-mail: muxailodmutryk@gmail.com } \\
\text { https://orcid.org/0000-0002-6291-981 }\end{array}$} \\
\hline 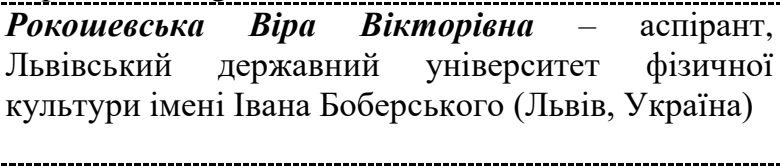 & $\begin{array}{l}\text { Rokoshevska Vira Viktorivna - Candidate of Science } \\
\text { in Physical Education and Sports, Head of the } \\
\text { Department of Physical Therapy and Ergotherapy at } \\
\text { Ukrainian Catholic University, (Lviv, Ukraina) }\end{array}$ \\
\hline & \\
\hline
\end{tabular}

